\title{
TEMPERATURE-DEPENDENCE OF NEURONAL PERFORMANCE IN THE MOTION PATHWAY OF THE BLOWFLY CALLIPHORA ERYTHROCEPHALA
}

\author{
ANNE-KATHRIN WARZECHA*, WOLFRAM HORSTMANN AND MARTIN EGELHAAF \\ Lehrstuhl für Neurobiologie, Fakultät für Biologie, Universität Bielefeld, Postfach 1001 31, 33501 Bielefeld, \\ Germany \\ *e-mail: ak.warzecha@biologie.uni-bielefeld.de
}

Accepted 6 September; published on WWW 28 October 1999

\begin{abstract}
Summary
Raising the head temperature within a behaviourally relevant range has strong effects on the performance of an identified neuron, the $\mathrm{H} 1$ neuron, in the visual motion pathway of blowflies. The effect is seen as an increase in the mean amplitude of the responses to motion under both transient and steady-state conditions, a considerable decrease in the response latency and an improvement in the

changes in the neuronal response properties with temperature may be of immediate functional significance for the animal under its normal operating conditions. In particular, the decrease in latency and the improvement in the reliability with increasing temperature may be relevant for the fly when executing its extremely virtuosic flight manoeuvres.
\end{abstract} reliability of the responses to motion. These temperaturedependent effects are independent of whether the animal is exposed to transient temperature changes or is maintained continuously at the same temperature for its entire life. The

Key words: temperature, insect, vision, motion-sensitive neurone, electrophysiology, blowfly, Calliphora erythrocephala.

\section{Introduction}

Given the fact that the rate of all biochemical reactions depends greatly on temperature, it is not surprising that physiological processes, including those operating in the nervous system, are considerably affected by temperature changes. In a number of systems, it can be shown that, for instance, the activation and inactivation of ion channels in neuronal membranes, the conduction velocity of action potentials, presynaptic transmitter release and postsynaptic reception change considerably as the temperature of the nervous system changes (for reviews, see Montogomery and Macdonald, 1990; Hille, 1992; Janssen, 1992).

Despite this sensitivity of neurons and neuronal connections to temperature changes, the nervous systems of poikilothermic animals are able to operate over a wide range of temperatures since these animals inhabit different habitats ranging from pack-ice-covered seas and high mountain areas to tropical waters and even deserts. In addition, in some habitats, animals must be able to cope with tremendous climatic changes during the course of a day or the cycle of the year. Long-term changes in temperature may lead to physiological acclimatisation of the organism, so that it can compensate for temperature-induced variations in neuronal function.

Even in poikilotherms, body temperature, and thus the temperature of the nervous system, is not exclusively determined by the ambient temperature. Animals can modify their body temperature by metabolic heat production during muscular activity (Cossins and Bowler, 1987) as well as by evaporative heat loss (Roberts and Harrison, 1999). In both free and tethered flying insects, temperature changes elicited during flight activity are particularly pronounced and are well documented (Stavenga et al., 1993; Heinrich, 1993). Since, in flying insects, metabolic heat is mainly produced by the huge flight muscles that constitute large parts of their thorax, the activity-dependent temperature changes may be expected to occur mainly in the thorax rather than in the abdomen or head. However, both these body compartments show temperature increases above the temperature of the environment. The head temperature of tethered flying blowflies (Stavenga et al., 1993) and of free-flying bees (Roberts et al., 1998; Schmaranzer and Kovac, 1996; Heinrich, 1993) increases considerably during flight. In flies, the head warms up to $27-28^{\circ} \mathrm{C}$ with a time constant of approximately $30 \mathrm{~s}$, at least at an ambient temperature of $25^{\circ} \mathrm{C}$ (Stavenga et al., 1993). In both flies and bees, the abdominal temperature also increases to some extent during flight, but stays lower than the head temperature. Interestingly, during steady flight, the temperature in all three body compartments of honeybees was found to be largely independent of the ambient temperature, at least up to an environmental temperature of $25^{\circ} \mathrm{C}$ (Schmaranzer and Kovac, 1996). In insects, most parts of the nervous system reside in the head and the thorax, so that neuronal performance may well be susceptible to the consequences of activity-dependent temperature changes in these body compartments.

Temperature-dependent changes in neuronal performance 


\section{A.-K. WARZECHA, W. Horstmann AND M. EgelhaAF}

have been demonstrated in some detail in the visual system of insects, especially in blowflies, at the photoreceptor level (French and Järvilehto, 1978; Weckström et al., 1985; Roebroek et al., 1990; Tatler et al., 1999). Most notably, when the temperature is increased from 16 to $30^{\circ} \mathrm{C}$, i.e. within the activity range of blowflies, the photoreceptor responses to light get much faster. These changes in the dynamic response properties of photoreceptors with temperature should have immediate functional consequences for the performance of the subsequent processing stages in the visual system, but this behaviourally relevant aspect of visual information processing has yet to be analysed. The present study, therefore, addresses the consequences of temperature changes on neuronal information processing in an individually identifiable neuron, the $\mathrm{H} 1$ cell, in the visual motion pathway of the blowfly. There are a number of features that render the blowfly particularly suitable for this analysis: (i) information is available about temperature effects at the input level of the visual system (see above); (ii) the range and time course of temperature changes elicited by the activity of flies during tethered flight is well documented (Stavenga et al., 1993); (iii) experiments on free and tethered flying animals have provided information on the visually guided orientation behaviour of the fly and thus on the functional context in which the nervous system has to operate (for a review, see Egelhaaf and Borst, 1993); (iv) neuronal circuits mediating at least some components of orientation behaviour are well characterised (for reviews, see Hausen, 1981; Hausen and Egelhaaf, 1989; Egelhaaf and Borst, 1993); and (v) the H1 neuron (Eckert, 1980; Hausen, 1981), which forms a constituent part of these circuits, can be recorded from for extended periods, allowing a systematic analysis of the temperature-dependence of neuronal performance.

In this study, the $\mathrm{H} 1$ neuron was used as a model system to address the following questions. (i) What are the consequences of temperature changes within a behaviourally relevant range on the activity level of the cell and its dynamic response properties? (ii) Do changes in body temperature affect the reliability of neural responses? (iii) Do flies acclimate to changes in ambient temperature and, in particular, is the neuronal performance differentially affected by transient and long-term exposure to a given temperature regime?

\section{Materials and methods}

The experiments were carried out on 2- to 14-day-old female blowflies (Calliphora erythrocephala Meigen). The animals were obtained from our laboratory stocks held at temperatures of between 22 and $25^{\circ} \mathrm{C}$ with a $16 \mathrm{~h}$ : $8 \mathrm{~h}$ light:dark photoperiod. Experiments were performed during the light cycle at least $2 \mathrm{~h}$ after light onset and no later than $5 \mathrm{~h}$ before light offset.

\section{Electrophysiology}

The spike activity of the directionally selective, motionsensitive H1 neuron (Eckert, 1980; Hausen, 1981) was recorded extracellularly in its output region in the third visual neuropile contralateral to the stimulated eye. The animals were dissected as described in detail previously (Warzecha et al., 1993). Electrophysiological recordings were made using electrolytically sharpened tungsten electrodes. The electrodes were insulated with nail polish and had resistances of approximately $4 \mathrm{M} \Omega$. As an indifferent electrode, a glass electrode with its tip broken was filled with Ringer's solution (for composition, see Hausen, 1982) and inserted into the haemolymph of the head capsule. Recorded signals were bandpass-filtered and amplified using standard electrophysiological equipment. Extracellularly recorded spikes were transformed into pulses of fixed height and duration. These pulses were fed into a PC through an analogto-digital converter of an I/O card (DT2801-A, Data Translation) at a sampling rate of $960 \mathrm{~Hz}$. Data were sampled and evaluated using programs written in ASYST (Keithley Instruments).

\section{Temperature control}

Two different temperature regimes were employed.

\section{Short-term temperature changes}

In these experiments, the effects of changes in head temperature were tested. Experiments were performed either at room temperature $\left(18-20^{\circ} \mathrm{C}\right)$ or at a high temperature $\left(26-28^{\circ} \mathrm{C}\right)$. To monitor the temperature, the sensor of an electronic thermometer (Conrad Electronics, Germany) was placed into the haemolymph of the head. To increase the temperature from room temperature to $26-28^{\circ} \mathrm{C}$, the head was illuminated through a small aperture by a lamp (halogen projection bulb, $12 \mathrm{~V}, 50 \mathrm{~W}$ ). The aperture was covered by a red filter (Schott RG8 and RG10) to prevent visual stimulation of the eyes. To control for the reversibility of the temperatureinduced effects, the temperature was decreased by switching the lamp off and then, in some cases, the temperature was increased again by turning the lamp on. In all cases, it took 10-15 min for the head temperature to level off at the intended value. As soon as the temperature was stable, data were collected again.

\section{Long-term temperature exposure}

To investigate the consequences of a constant low or high body temperature, experiments were performed in a climatic chamber, the temperature of which was held either at $19-20{ }^{\circ} \mathrm{C}$ or $29-30^{\circ} \mathrm{C}$. The animals were transferred from the normal breeding room into the climatic chamber after pupation and were kept there for the entire life of the adult fly until the experiments were completed.

\section{Visual stimulation}

The motion stimuli used in the experiments with short-term temperature changes and long-term exposure to a constant temperature were generated in different ways.

\section{Experiments with short-term temperature changes}

A vertical square-wave grating was generated on an 
oscilloscope screen (Tektronix 608) by an image synthesiser (Picasso, Innisfree) at a frame rate of $183 \mathrm{~Hz}$. Pattern movement was controlled via the image synthesiser by a PC. The horizontal extent of the screen was $74^{\circ}$ and the vertical extent was $59^{\circ}$. The centre of the screen was at an azimuth/elevation of $42 \% 0^{\circ}$, with $0 \% 0^{\circ}$ referring to the front midline of the animal. The front edge of the screen was at an angular position of $6^{\circ}$ and the lateral edge at $80^{\circ}$. The spatial wavelength of the grating was $10.6^{\circ}$, the mean luminance was $1.4 \mathrm{~cd} \mathrm{~m}^{-2}$ and the contrast was 0.89 . The pattern was moved at constant velocities in the preferred direction of the cell at temporal frequencies ranging between 0.5 and $32 \mathrm{~Hz}$. Data acquisition was triggered with the frame synchronisation signal of the image synthesiser. Spontaneous activity was recorded for $1 \mathrm{~s}$ before a motion stimulus was presented. The exact stimulus protocol was different for the different experiments. In some experiments (see Figs 1A, 2, 3), seven stimuli moving at different temporal frequencies were shown in a pseudorandom order before the next sequence started. Presentation of these motion stimuli was interrupted by $5 \mathrm{~s}$ intervals during which the pattern was stationary. Thirty trials were usually recorded per stimulus condition, temperature and cell, but recordings were sometimes stopped after only a few trials if recording quality deteriorated. In other experiments, the results of which are shown in Figs 1B and 4, motion at $20 \mathrm{~Hz}$ and $4 \mathrm{~Hz}$ was presented alternately for $3 \mathrm{~s}$ interrupted by an interstimulus interval of $5.5 \mathrm{~s}$ during which the pattern was stationary. In these experiments, it was intended to analyse the statistical properties of the individual spike responses, so at least 50 response trials were recorded per stimulus condition, temperature and cell. It should be noted that, because of the methodological differences between different experiments, data can be compared quantitatively only within a given data set.

\section{Experiments at constant temperature}

Stimuli were displayed via an array of light-emitting diodes (LEDs) which consisted of 48 columns of 30 quasi-rectangular LEDs per column. Because of the particular shape of the LEDs, there was virtually no space between neighbouring LEDs. The horizontal angular extent of the LED array amounted to $35^{\circ}$, while the vertical angular extent was $42^{\circ}$. The LED array was placed in the receptive field of the $\mathrm{H} 1$ neuron symmetrically with respect to the equator of the eye. The front edge of the LED array was at an angular position of $15^{\circ}$ and the lateral edge at $50^{\circ}$. The stimulus pattern consisted of a square-wave grating with a spatial wavelength of $8.8^{\circ}$, a mean luminance of $400 \mathrm{~cd} \mathrm{~m}^{-2}$ and a contrast of almost 1 . The pattern was displaced horizontally by one LED column at each time step, leading to apparent motion stimuli. These motion stimuli elicited pronounced direction-selective responses in the $\mathrm{H} 1$ neuron that were virtually indistinguishable from responses elicited by motion stimuli generated on an oscilloscope screen. Apparent motion was presented at a constant temporal frequency of $11 \mathrm{~Hz}$. Eighty trials were usually recorded from each fly. In each trial, the pattern was initially stationary for
$1 \mathrm{~s}$, it was then moved for $3 \mathrm{~s}$ in the preferred direction of the cell and finally held stationary again for $5 \mathrm{~s}$ before the next trial started.

\section{Data evaluation \\ Evaluation of the latency}

The spike frequency histograms of individual cells were smoothed using a Blackman filter with a cut-off at $120 \mathrm{~Hz}$ (Blackman and Tukey, 1958; Astheimer, 1989). We then determined the time, starting $6.2 \mathrm{~ms}$ after the onset of motion, at which the smoothed spike frequency of the cell exceeded a threshold value. This time was taken as the latency of the response of the cell. The threshold value was chosen as the mean spontaneous activity of the cell plus six times the standard deviation of the spike frequency histogram from its respective time-averaged value when no motion stimulus was presented. Using a smaller threshold as a criterion for the latency (three times the standard deviation) did not always yield a meaningful value because of sudden changes in the spontaneous activity. In those cells in which both criteria could be applied (more than $85 \%$ of all cells), there was an average difference between the latencies determined for the two criteria of between 1.75 and $1.91 \mathrm{~ms}$ for the different data sets.

\section{Evaluation of the transient response following the onset of a motion stimulus}

The amplitude of the transient response was determined as the maximal value in the smoothed spike frequency histogram of each cell within a time interval corresponding to threequarters of the temporal period of the motion stimulus, i.e. the inverse of the temporal frequency, corrected for the latency of the cell. This means, for instance, for a temporal frequency of $2 \mathrm{~Hz}$ that the response maximum was determined within a time interval of $375 \mathrm{~ms}$. Spike frequency histograms of each cell were smoothed using a Blackman filter with a cut-off at $120 \mathrm{~Hz}$ (Blackman and Tukey, 1958; Astheimer, 1989).

\section{Evaluation of the signal-to-noise ratio}

The signal-to-noise ratio was determined for an early and a late phase of the time-dependent responses as the ratio of the mean response (signal) to its standard deviation across trials (noise). The neural activity during the first $100 \mathrm{~ms}$ following the latent period was taken as the early response. The late response was determined within 10 consecutive nonoverlapping $100 \mathrm{~ms}$ integration windows during the third second after motion onset. To measure the signal, the spontaneous activity recorded before the onset of motion was subtracted from the responses during motion. The noise was calculated as the standard deviation of the individual responses across trials from the mean response within the same window. The signal-to-noise ratio was determined for each of the integration windows separately. To obtain the signal-to-noise ratio for a given cell during the late response phase, the values for the 10 consecutive windows were averaged. The only cells analysed were those that were approximately 'stationary' for at least 50 consecutive trials. The criterion used to identify 
Fig. 1. Responses of the $\mathrm{H} 1$ neuron at low $\left(18-20^{\circ} \mathrm{C}\right)$ and high $\left(26-28^{\circ} \mathrm{C}\right)$ temperatures. (A) Time course of the responses to motion in the preferred direction of the cell. Motion starts at time zero. After a brief transient phase, the response reaches a steady-state level. Both the transient and the steadystate responses are much larger at high $t$ than at low temperatures. Spike frequency histograms were obtained from 14 neurons and 441 individual responses for the low temperature and 332 responses for the high temperature. The mean steady-state response and its standard deviation are indicated in the right part of the figure for both

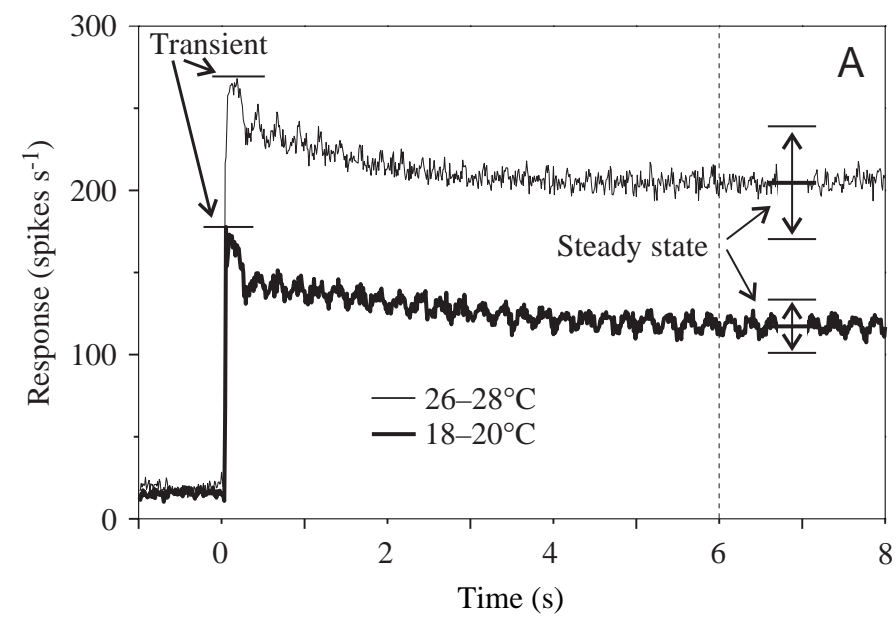
temperature regimes. The response maximum of the smoothed spike frequency histogram within a given time interval after the onset of motion was taken as the transient response (see Materials and methods). The mean transient response and its standard deviation amounted to $192.7 \pm 19.3$ spikes s $^{-1}$ for the low temperature and $283.5 \pm 26.5$ spikes s$^{-1}$ for the high temperature. These values are somewhat larger than can be inferred from the responses shown in A because the maximal response was determined for each cell separately and does not occur at exactly the same instant for each cell. The temporal frequency of stimulus motion was $4 \mathrm{~Hz}$; the temporal resolution of the spike frequency histogram is $10.4 \mathrm{~ms}$. For 11 cells, responses were first recorded at the low temperature and then at the high temperature. Three H1 neurons were heated in the first part of the experiment so that their responses to motion at the low temperature were recorded after their responses at the high temperature. The sequence of recording, i.e. starting with the high or the low temperature, did not influence the results. (B) Reversibility of the temperature effect. Spontaneous activity (Spont.) and mean response to motion (temporal frequency $4 \mathrm{~Hz}$ ) are shown at $19{ }^{\circ} \mathrm{C}$, after increasing the temperature to $28^{\circ} \mathrm{C}$ and after decreasing the temperature to $19^{\circ} \mathrm{C}$ again. The values are the mean responses of a single $\mathrm{H} 1 \mathrm{neuron}$ during a $2 \mathrm{~s}$ interval starting $1 \mathrm{~s}$ after the onset of motion to 50 stimulus presentations.

stationary cells was that the mean response to motion did not show a large trend, i.e. did not increase or decrease by more than 0.15 spikes s $^{-1}$ trial $^{-1}$ as determined by regression analysis over the mean activity of those trials that were used for further analysis.

\section{Testing the significance of temperature effects}

To test whether changes in temperature significantly affect the properties of the H1 neuron, Wilcoxon's signed-ranks test for two groups arranged as paired observations was employed. When testing whether exposure to a constant temperature significantly affects the properties of the $\mathrm{H} 1$ neuron, the Wilcoxon two-sample test was used (Sokal and Rohlf, 1981; Rohlf and Sokal, 1981).

Further descriptions of how the data were evaluated are given in the Results section or the figure legends.

\section{Results}

The effects of temperature on the response properties of an identified motion-sensitive neuron, the $\mathrm{H} 1$ cell, were analysed in the blowfly Calliphora erythrocephala. The responses of this neuron to motion were determined at room temperature $\left(18-20^{\circ} \mathrm{C}\right)$ and at a temperature between 26 and $30^{\circ} \mathrm{C}$. In some experiments, the temperature of the head of the fly was increased only transiently. In other experiments, the ambient temperature was kept at a constant level for the entire posthatching life of the flies. In the latter experiments, two different steady temperatures were chosen to determine whether the neuronal properties acclimate or whether similar effects of temperature can be observed in constant and in transient conditions.

\section{Motion-induced responses and spontaneous activity}

The most obvious consequence of raising head temperature is a considerable increase in the overall response to motion in the preferred direction of the cell. After the onset of motion at constant velocity in the preferred direction of the cell (backto-front motion), the spike frequency increases rapidly and, after a transient phase, reaches a more-or-less constant response level (Fig. 1A). The spike frequency during both the transient and steady-state phases is much higher after increasing the temperature from room temperature to the high temperature. This observation holds for each individual cell tested. On average, the spontaneous firing rate of the neuron, determined over $1 \mathrm{~s}$ before the onset of motion, increases slightly from $14.3 \pm 7.8$ spikes s $^{-1}$ at $18-20^{\circ} \mathrm{C}$ to $18.9 \pm 10.6$ spikes s $^{-1}$ at $26-28^{\circ} \mathrm{C}$ (mean \pm S.D., $N=14$; same data set as that used for Fig. 2). However, the spontaneous activity was greater at the high than at the low temperatures for only six out of 14 cells tested (Fig. 1A, compare with Figs 1B, 4A). The slight increase in the mean spontaneous activity at $26-28^{\circ} \mathrm{C}$ is, therefore, not statistically significant. During motion in the null direction (front-to-back motion), the H1 neuron is inhibited. This characteristic is not altered by temperature increases (data not shown), indicating that the directional selectivity of the $\mathrm{H} 1$ neuron is maintained during temperature changes. The temperature-dependent effects were 
Temperature effects on neuronal performance 3165

Fig. 2. Dependence of H1 neuron responses on temporal frequency under both steady-state (A) and transient (B) conditions at $18-20^{\circ} \mathrm{C}$ and $26-28^{\circ} \mathrm{C}$. The transient response was determined as described in Materials and methods. The steady-state response was determined by averaging the response during a $2 \mathrm{~s}$ time interval starting $6 \mathrm{~s}$ after the onset of motion. At all temporal frequencies, both the transient and the steady-state responses were much larger at the high than at the low temperatures $(P<0.005)$. Values are means \pm S.E.M. from 14 cells for 441 individual responses at $18-20^{\circ} \mathrm{C}$ and 332 individual responses at $26-28^{\circ} \mathrm{C}$.

found to be fully reversible (Fig. 1B). When the head temperature was reduced, after keeping the head at the higher temperature for approximately $30 \mathrm{~min}$, the response amplitudes return to their previous room temperature level. Further experiments in which the responses under the hightemperature condition were measured before the responses under the low-temperature condition corroborate the reversibility of transient temperature effects (not shown, data included in Fig. 1A).

\section{Velocity-dependence}

As is characteristic of motion-sensitive neurons, the response of the $\mathrm{H} 1$ neuron depends on the velocity of the stimulus. The response increases with increasing temporal frequency, reaches a maximum and then decreases again (Eckert, 1980; Hausen, 1981; Maddess and Laughlin, 1985). The responses elicited by a range of temporal frequencies were determined to test whether the velocity-dependence of the $\mathrm{H} 1$ cell's responses is affected by changes in head temperature. Since the transient and steady-state response amplitudes differ considerably, especially at high temporal frequencies (Maddess and Laughlin, 1985; Egelhaaf and Borst, 1989), both were determined separately from the spike frequency histogram obtained for each temporal frequency. Both the transient and the steady-state response amplitudes were considerably larger at $26-28^{\circ} \mathrm{C}$ than at $18-20^{\circ} \mathrm{C}$ (Fig. 2, $P<0.005)$. The two responses do not depend on the temporal frequency in the same way. The transient responses increase over almost the entire range of temporal frequencies tested (Fig. 2B), whereas the steady-state responses increase with temporal frequency, reach a maximum and then decrease (Fig. 2A). The maximum of the steady-state responses is shifted from $2 \mathrm{~Hz}$ at room temperature to $4 \mathrm{~Hz}$ at $26-28^{\circ} \mathrm{C}$.

\section{Response latency}

How well an animal can react to moving stimuli depends not only on its sensitivity to stimulus velocity but also on its response latency. Short latencies are particularly important if the animal has to respond to rapid changes in visual input. For this reason, the effects of changes in head temperature on the latency of the response to the onset of motion were examined. Although it is somewhat arbitrary to determine the exact onset of the response, it is immediately obvious that the latency is shorter at $26-28^{\circ} \mathrm{C}$ than at $18-20^{\circ} \mathrm{C}$. Using the criterion specified in Materials and methods, the latency is reduced from $31.7 \pm 2.3 \mathrm{~ms}$ at $18-20^{\circ} \mathrm{C}$ to $23.4 \pm 1.5 \mathrm{~ms}$ at $26-28^{\circ} \mathrm{C}$ (mean \pm S.D, $N=14, P<0.005$ ) (Fig. 3). The latency of each individual cell was reduced by at least $6.2 \mathrm{~ms}$ at the high temperature. On average, the latency was reduced by almost one-third by a temperature shift from approximately 19 to $27^{\circ} \mathrm{C}$. Although the latency depends on the exact stimulus conditions (A.-K. Warzecha and M. Egelhaaf, in preparation), a similar decrease in latency with increasing temperature was found for the other temporal frequencies tested (not shown).

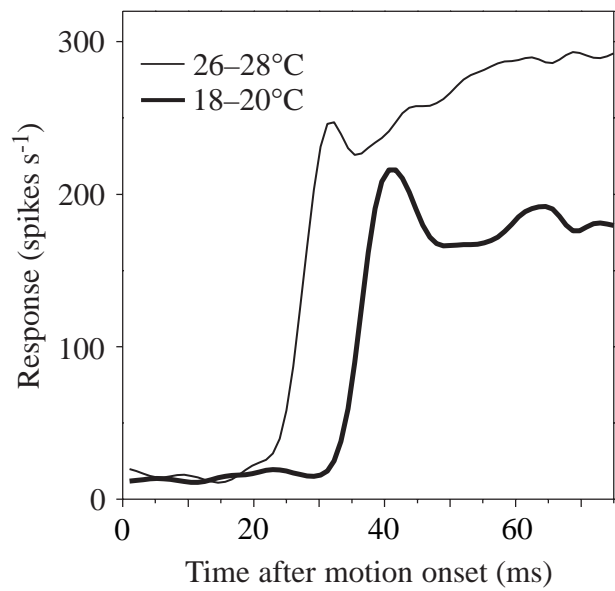

Fig. 3. Time course of the onset of the response to stimulus motion at low $\left(18-20^{\circ} \mathrm{C}\right)$ and high $\left(26-28^{\circ} \mathrm{C}\right)$ temperatures. The response latency (for evaluation, see Materials and methods) is reduced by approximately $8 \mathrm{~ms}$ when the temperature is increased. Mean spike frequency histogram of 14 cells (same data set as in Fig. 2) at a temporal frequency of stimulus motion of $8 \mathrm{~Hz}$. 


\section{A.-K. Warzecha, W. Horstmann and M. EgelhaAF}

Fig. 4. Reliability of neural responses to motion at low $\left(18-20^{\circ} \mathrm{C}\right)$ and high $\left(26-28^{\circ} \mathrm{C}\right)$ temperatures. Three $\mathrm{H} 1$ neurons (total number of trials 150) were stimulated alternately at temporal frequencies of $4 \mathrm{~Hz}$ and $20 \mathrm{~Hz}$. An early and a late phase of the responses were analysed. Early responses comprised the first $100 \mathrm{~ms}$ of the response following the latency period. Late responses were evaluated during the third second after motion onset. (A) Mean responses. The horizontal lines denote spontaneous (Spont.) activity. Early response: at a temporal frequency of $4 \mathrm{~Hz}$, the activities of the individual cells ranged between 128 and 172 spikes s $^{-1}$ at $18-20^{\circ} \mathrm{C}$ and between 224 and 295 spikes s $^{-1}$ at $26-28^{\circ} \mathrm{C}$. At a temporal frequency of $20 \mathrm{~Hz}$, the activities of the

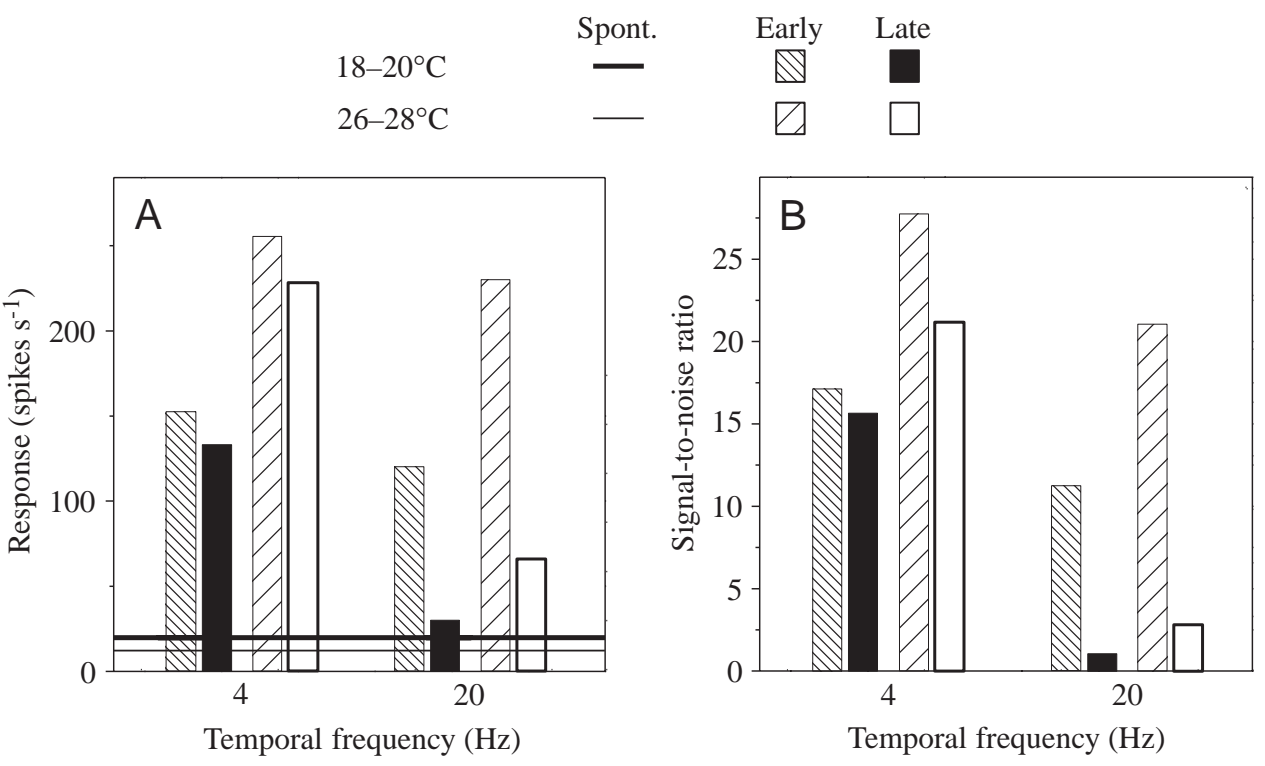
individual cells ranged between 103 and 130 spikes s ${ }^{-1}$ at $18-20^{\circ} \mathrm{C}$ and between 202 and 250 spikes s ${ }^{-1}$ at $26-28^{\circ} \mathrm{C}$. The values increased with temperature for every cell and temporal frequency $(P<0.005)$. Late response: at a temporal frequency of $4 \mathrm{~Hz}$, the activities of the individual cells ranged between 121 and 152 spikes s$^{-1}$ at $18-20^{\circ} \mathrm{C}$ and between 190 and 248 spikes s$^{-1}$ at $26-28^{\circ} \mathrm{C}$. At a temporal frequency of $20 \mathrm{~Hz}$, the activities of the individual cells ranged between 15 and 52 spikes s${ }^{-1}$ at $18-20^{\circ} \mathrm{C}$ and between 55 and 87 spikes s$^{-1}$ at $26-28^{\circ} \mathrm{C}$. The values increased with temperature for every cell and temporal frequency, but were not statistically significant for one cell at $20 \mathrm{~Hz}$. (B) Signal-to noise ratios calculated from responses within the first $100 \mathrm{~ms}$ following the latent period (early response) and 10 consecutive non-overlapping $100 \mathrm{~ms}$ time windows starting $2 \mathrm{~s}$ after the onset of motion (late response). Early response: at a temporal frequency of $4 \mathrm{~Hz}$, the signal-to-noise ratios of the individual cells ranged between 13.5 and 20.1 at $18-20^{\circ} \mathrm{C}$ and between 20.7 and 33.6 at $26-28^{\circ} \mathrm{C}$. At a temporal frequency of $20 \mathrm{~Hz}$, the signal-to-noise ratios of the individual cells ranged between 7.9 and 13.6 at $18-20{ }^{\circ} \mathrm{C}$ and between 18.8 and 23.5 at $26-28{ }^{\circ} \mathrm{C}$. For each cell, the signal-to-noise ratio was larger at the high than at the low temperature. Late response: at a temporal frequency of $4 \mathrm{~Hz}$, the signal-to-noise ratios of the individual cells ranged between 12.1 and 20.1 at $18-20^{\circ} \mathrm{C}$ and between 17.4 and 25.8 at $26-28^{\circ} \mathrm{C}$. At a temporal frequency of $20 \mathrm{~Hz}$, the signal-to-noise ratios of the individual cells ranged between 0.7 and 1.4 at $18-20^{\circ} \mathrm{C}$ and between 1.5 and 4.4 at $26-28^{\circ} \mathrm{C}$. For each cell, the signal-to-noise ratio was larger at the high than at the low temperature.

Temperature changes have little effect on the slope of the response at motion onset.

\section{Reliability of encoding motion information}

The increase in the mean response amplitude with temperature per se does not imply that motion stimuli are represented more reliably at higher temperatures. Only when the variability of the responses increases less than the mean response amplitude can different stimuli be distinguished better, i.e. the reliability of the representation of motion improves. The mean response to motion and the signal-to-noise ratio, i.e. the ratio of the mean response to its standard deviation, were determined at two temporal frequencies, $4 \mathrm{~Hz}$ and $20 \mathrm{~Hz}$, during the early and late response phases (Fig. 4). The data were taken from a different set of experiments from those in which the temporal frequency was varied systematically to obtain responses to a sufficiently large number of stimulus presentations to give a reliable estimate of the signal-to-noise ratio. Since the mean spike activity was often not stationary across trials according to our criterion (see Materials and methods), only three out of eight recorded cells could be used for this analysis.

In accord with Fig. 2A, the mean response amplitude during the third second after motion onset (late response phase) is smaller for the faster-moving stimulus than for the stimulus moving at $4 \mathrm{~Hz}$ and increases with increasing temperature for both temporal frequencies (Fig. 4A). For the early phase of motion-induced activity, the responses to motion at a temporal frequency of $20 \mathrm{~Hz}$ are only slightly smaller than the responses to motion at $4 \mathrm{~Hz}$ (Fig. 4A). The temperature-induced increase in the mean activity is statistically significant for both response phases and all three cells tested $(P<0.005)$ apart from one cell at $20 \mathrm{~Hz}$ during the late phase. The signal-to-noise ratio is smaller at the higher temporal frequency than at the lower one; it increases with temperature at both temporal frequencies (Fig. 4B). The relatively small signal-to-noise ratio during the late response phase at the high temporal frequency is due to the small motion-induced response and a standard deviation larger than that determined at $4 \mathrm{~Hz}$. These observations apply to each of the three cells analysed.

\section{Consequences of constant temperature exposure}

In general, neuronal performance does not acclimate when the animals are kept at a given temperature. This conclusion can be drawn from experiments in which the animals were kept at either $19-20^{\circ} \mathrm{C}$ or $29-30{ }^{\circ} \mathrm{C}$ for their entire life after pupation. The main results of these experiments are summarised in Fig. 5. The distributions of the mean levels of 
Fig. 5. Effects of constant temperature exposure on the $\mathrm{H} 1$ neuron. Each distribution is normalised to an area of 1. (A) Distributions of mean responses to motion stimulation at low $\left(19-20^{\circ} \mathrm{C}\right)$ and high $\left(29-30^{\circ} \mathrm{C}\right)$ temperatures. Responses recorded during the third second after motion onset are evaluated. (B) Distributions of response latencies at low and high temperatures. Latency was determined as specified in Materials and methods. (A,B) Data from 41 cell with 3235 individual response traces at $19-20^{\circ} \mathrm{C}$ and 31 cells with 2440 individual response traces at 29-30 ${ }^{\circ}$ C. (C) Distributions of signalto-noise ratios at low and high temperatures during the late response phase. Data from $34 \mathrm{H} 1$ neurons with 2492 individual response traces at 19-20 ${ }^{\circ} \mathrm{C}$ and $26 \mathrm{H} 1$ neurons with 1863 individual response traces at $29-30^{\circ} \mathrm{C}$.
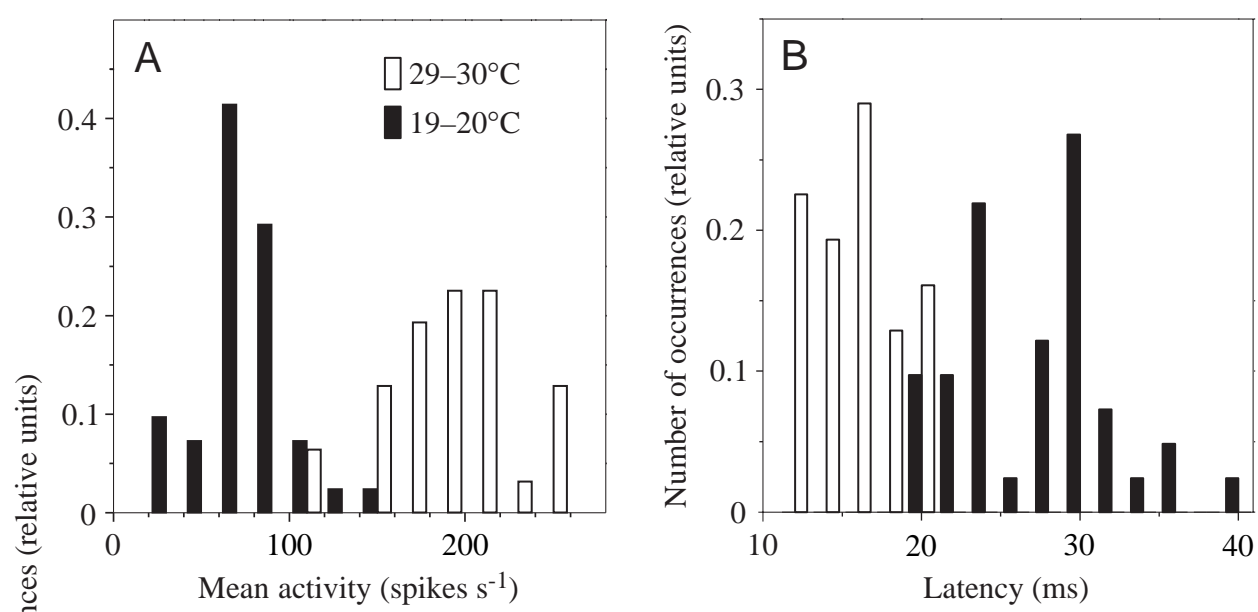

activity obtained in different animals (Fig. 5A) demonstrate that, at a given temperature, the mean activity induced by a particular motion stimulus can differ by more than a factor of two in different individuals. Nevertheless, the distribution obtained for the high temperature is shifted to higher activites compared with the distribution obtained for the low temperature $(P<0.0005)$. This observation applies both to the activity during the first $100 \mathrm{~ms}$ following the latent period (early response, not shown) and to the activity during the third second after motion onset (late response, Fig. 5A). The mean activity increased with the temperature from 138.8 to 268 spikes s$^{-1}$ for the early response and from 76.4 to 190.3 spikes s $^{-1}$ for the late response. Compared with motioninduced activity, the spontaneous activity increased only weakly with temperature (low temperature $15.1 \pm 8.5$ spikes s$^{-1}$; high temperature $39.2 \pm 21.1$ spikes s $^{-1}$; mean \pm S.D.; $N=41$ cells at $19-20^{\circ} \mathrm{C}, N=31$ cells at $29-30^{\circ} \mathrm{C}, P<0.005$ ). The relatively large standard deviations indicate that the distributions of the spontaneous activities obtained for the low and high temperatures overlap considerably. The response latency was found to be significantly smaller, on average by $11.6 \mathrm{~ms}$, in animals reared at the high temperatures (mean latency $14.7 \mathrm{~ms}$ ) than in animals reared at $19-20^{\circ} \mathrm{C}$ (mean latency $26.3 \mathrm{~ms}$; $P<0.0005$; Fig. 5B). In addition, the signal-to-noise ratio of the responses was larger at high temperatures than at lower ones
(Fig. 5C), because the increase in response variability with temperature is smaller than the corresponding increase in the mean response amplitude. The mean signal-to-noise ratio increased significantly with temperature from 11.9 to 15.5 for the early response (not shown) and from 4.7 to 7.9 for the late response $(P<0.005)$. It should be noted that the results obtained for long-term temperature exposure should not be compared quantitatively with those obtained after transient temperature changes because the visual stimuli that were used in the two sets of experiments differed in important details (see Materials and methods). In any case, these results clearly show that the performance of the $\mathrm{H} 1$ neuron is temperature-dependent. A comparison with effects elicited by transient temperature changes indicates that temperature-dependent performance is independent of the time scale over which temperature changes take place. Hence, at the level of the $\mathrm{H} 1$ neuron, there are no indications of any pronounced acclimation of the visual system.

\section{Discussion}

The knowledge that temperature affects all chemical reactions and, thus, also those occurring in an animal, does not allow predictions to be made about how temperature will affect the overall performance of neurons. In the present study, three major 


\section{A.-K. WARZECHA, W. Horstmann AND M. EgElHAAF}

effects were found in the responses of an identified interneuron in the fly visual system to motion stimulation when the temperature was raised from the lower end of the normal activity range of the fly $\left(18-20^{\circ} \mathrm{C}\right)$ towards its upper end $\left(26-30^{\circ} \mathrm{C}\right)$. These effects were as follows: (i) the response amplitudes increase considerably under all stimulus conditions tested here (Figs 1, 2); (ii) the latency of the motion-induced responses is reduced by approximately $8-10 \mathrm{~ms}$ irrespective of temporal frequency (Fig. 3); and (iii) the signal-to-noise ratio of motioninduced responses increases. The relative increase in the signalto-noise ratio is especially pronounced at high temporal frequencies (Fig. 4). Interestingly, none of these temperaturedependent effects acclimates: they are, at least qualitatively, the same irrespective of whether the fly is only transiently exposed to a different head temperature or is kept at a given temperature for its entire post-larval life (Fig. 5). In contrast, acclimation effects on the physiological properties of neurons have been described in a wide range of animals (Janssen, 1992).

\section{Possible reasons for the temperature effects found in the fly}

An elevated response amplitude of the $\mathrm{H} 1$ neuron with increasing temperature may be caused by a raised response amplitude of the photoreceptors, by an increased synaptic gain in the peripheral visual system or by an increased excitability resulting from changes in the spike-generation mechanism of the $\mathrm{H} 1$ cell itself. Photoreceptor responses of the fly have been found to increase dramatically with increasing temperature. This has been shown for a much lower temperatures range (between 4 and $20^{\circ} \mathrm{C}$ ) than was tested in the present study (French and Järvilehto, 1978; Weckström et al., 1985), but also for the behavioural operating range of flies, where the responses have been shown to increase in the light-adapted state by approximately $65 \%$ between 19 and $34^{\circ} \mathrm{C}$ (Tatler et al., 1999; see, however, Roebroek et al., 1990). Such a temperature-dependent increase in the photoreceptor response amplitude could well be the main reason for the increase in the activity of the H1 neuron with temperature. Of course, additional temperature-dependent changes in the nervous system, such as changes in synaptic gain, may augment this effect. The evidence for changes in synaptic gain in poikilothermic animals is quite inconclusive, however, and depends on the preparation under investigation and the temperature range analysed (for reviews, see Montgomery and Macdonald, 1990; Janssen, 1992). This is not surprising because the gain of a synaptic connection is made up of a series of contributing processes that may have different temperature characteristics. Moreover, temperature does not affect the excitability of neurons in a consistent way (for reviews, see Montgomery and Macdonald, 1990; Janssen, 1992). The finding that in the $\mathrm{H} 1$ neuron the spontaneous spike activity does not increase consistently with temperature may be an indication that the spike threshold and, therefore, the excitability are little affected by temperature changes. Hence, on the basis of the available evidence, an increased sensitivity of the photoreceptors is likely to be the main source of the increased sensitivity of the H1 neuron to visual motion.
The activity of another type of motion-sensitive neuron in the fly, the so-called FD cell, which responds most vigorously to motion of small objects (Egelhaaf, 1985a), does not depend consistently on temperature (Kimmerle, 1999). Similarly, in locusts, the so-called DCMD neuron, which reliably transmits spikes from a neuron termed LGMD to the thoracic ganglia, does not change its spiking activity significantly with temperature increases of approximately $10^{\circ} \mathrm{C}$ (Gabbiani et al., 1999). Both types of neuron, the FD cells and the LGMD neuron, not only pool the signals from many retinotopically organised input elements, as is assumed to be the case for the H1 neuron, but, in addition, receive inhibitory input from large-field neurons (Rowell et al., 1977; Egelhaaf, 1985b; Warzecha et al., 1993). Hence, inhibitory interactions between different large-field neurons may cause the invariance of the response amplitudes of the cells to changing temperature. Further experiments are needed to assess whether other output elements of the visual motion-detection pathway that are not inhibited by large-field elements depend on temperature in a manner similar to that of the H1 neuron.

As already concluded for the elevated response amplitude of the H1 neuron, its decreased latency may also have major effects on the properties of the photoreceptor responses. At low temperature (French and Järvilehto, 1978; Weckström et al., 1985), but also in the behaviourally relevant temperature range tested in the present study, the time constants of light-induced responses of fly photoreceptors decrease with an increase in temperature, shifting their dynamic range towards higher temporal frequencies (Weckström et al., 1985; Tatler et al., 1999). In accord with this finding, the responses of locust ocellar second-order neurons are faster at elevated temperatures than at lower ones (Simmons, 1990). These effects are likely to lead to shorter response latencies at the level of motion-sensitive neurons. Interestingly, the decreases in the latency and the time-to-peak of light-induced photoreceptor responses (Weckström et al., 1985; Roebroek et al., 1990; Tatler et al., 1999) were found to be in the same range as the latency changes observed in the $\mathrm{H} 1$ neuron. Moreover, the changes in the response dynamics of the $\mathrm{H} 1$ cell with increasing temperature may also be affected by other factors. Changes in synaptic delays are generally found to decrease considerably with rising temperature (Katz and Miledi, 1965; Burrows, 1989; Simmons, 1990; Robertson, 1993). This reduction in synaptic delay may be caused, at least to a large extent, by an increased rate of transmitter release (e.g. Delaney and Zucker, 1990). Moreover, the conduction velocity of neural signals has been found to increase considerably at elevated temperatures (French, 1985; Janssen, 1992).

\section{Functional significance of the temperature effects}

The functional consequences of the observed temperaturedependent changes in the movement responses of the $\mathrm{H} 1$ neuron are particularly obvious for the increase in the signalto-noise ratio and the reduction in the response latency. Reliable and rapid responses to motion stimuli may be decisive in many situations, especially when the animal needs to escape 
from a predator or tries to catch a mate on the wing. The increase in the signal-to-noise ratio with temperature is particularly pronounced for stimuli that lead to only relatively small response amplitudes. Hence, the operating range of the motion-detecting system is increased at high temperatures compared with low ones. These considerations suggest that especially fast, visually guided flight manoeuvres by the fly may only be possible when the temperature of the nervous system is sufficiently high.

During flight, the head temperature of flies may be elevated to a larger extent than when they are walking, since the muscles in the thorax are more active. At the same time, flying flies are confronted with faster image motion and, therefore, possibly with higher temporal frequencies than walking flies. The increased sensitivity of the motion-analysis system to high temporal frequencies at high temperatures appears, therefore, to be adaptive. Moreover, since image motion may change more rapidly during flight than when walking, shorter temporal integration times must be employed by the nervous system to obtain an estimate of the current stimulus situation when the animal is flying. The increased signal-to-noise ratio in the neural responses found at high temperature might compensate for the restricted temporal averaging.

Decreased response latencies with increasing temperature may also be relevant in the context of mating behaviour when male flies chase females in often virtuosic flight manoeuvres (Land and Collett, 1974; Wagner, 1986). It is interesting that male flies seem to exhibit their chasing manoeuvres almost exclusively when the temperature of the flight arena is above $25^{\circ} \mathrm{C}$ (N. Böddeker, unpublished observation on Lucilia sp., Calliphoridae) and thus within a temperature range at which the nervous system performs with short latencies. In particular, male Lucilia that, under outdoor conditions, sit in ambush at an elevated location and dart at any moving female-like object with a rapid pursuit manoeuvre to catch it (R. Kern and N. Böddeker, unpublished observation) do not have the chance to raise their head and body temperature by flight activity before they start chasing and, thus, may be able to chase the female only when the ambient temperature is high. Moreover, previous investigations on chasing behaviour of male flies have been performed at temperatures above $25^{\circ} \mathrm{C}$ (Fannia canicularis, Land and Collett, 1974; Musca domestica, Wagner, 1986).

All these considerations on the functional significance of the reduction in the response latency and the increase in the signalto-noise ratio are based on the assumption that the neurons that control the above-mentioned behavioural reactions show temperature-dependent properties similar to those of the H1 neuron. This needs to be tested in future experiments. The H1 neuron is an intrinsic element of the neuronal circuits thought to mediate optomotor course stabilisation (Hausen, 1981; Horstmann et al., 1999) and object background discrimination (Egelhaaf et al., 1993). For optomotor course stabilisation, a reduction in the latency is advantageous because the risk of the control system becoming unstable is reduced (Warzecha and Egelhaaf, 1996).
We are grateful to Judith Eikermann and Monika Mielich for performing large parts of the electrophysiological experiments and for the maintenance of the animal stocks. Paul Meyer and Peter Hunger (Electronics Workshop of the Faculty of Biology, Universität Bielefeld) developed the LED array and its control, which was used for visual stimulation in part of the experiments. Thanks are also due to Roland Kern, Holger Krapp and Rafael Kurtz for critically reading the manuscript and for helpful discussions. Experiments comply with the Principles of Animal Care (NIH, 1985) and with the current laws of Germany.

\section{References}

Astheimer, J. P. (1989). Asyst: Module 2 - Analysis. Rochester, NY: Keithley Instruments.

Blackman, R. B. and Tukey, J. W. (1958). The Measurement of Power Spectra. New York: Dover.

Burrows, M. (1989). Effects of temperature on a central synapse between identified motor neurons. J. Comp. Physiol. A (Abstract) 165, 687-695.

Cossins, A. R. and Bowler, K. (1987). Temperature Biology of Animals. London, New York: Chapman \& Hall.

Delaney, K. R. and Zucker, R. S. (1990). Calcium released by photolysis of DM-nitrophen stimulates transmitter release at squid giant synapse. J. Physiol., Lond. 426, 473-498.

Eckert, H. (1980). Functional properties of the H1-neurone in the third optic ganglion of the blowfly, Phaenicia. J. Comp. Physiol. 135, 29-39.

Egelhaaf, M. (1985a). On the neuronal basis of figure-ground discrimination by relative motion in the visual system of the fly. II. Figure-detection cells, a new class of visual interneurones. Biol. Cybernetics 52, 195-209.

Egelhaaf, M. (1985b). On the neuronal basis of figure-ground discrimination by relative motion in the visual system of the fly. III. Possible input circuitries and behavioural significance of the FD-cells. Biol. Cybernetics 52, 267-280.

Egelhaaf, M. and Borst, A. (1989). Transient and steady-state response properties of movement detectors. J. Optic. Soc. Am. A 6 , 116-127.

Egelhaaf, M. and Borst, A. (1993). A look into the cockpit of the fly: Visual orientation, algorithms and identified neurons. $J$. Neurosci. 13, 4563-4574.

Egelhaaf, M., Borst, A., Warzecha, A.-K., Flecks, S. and Wildemann, A. (1993). Neural circuit tuning fly visual interneurons to motion of small objects. II. Input organization of inhibitory circuit elements by electrophysiological and optical recording techniques. J. Neurophysiol. 69, 340-351.

French, A. S. (1985). The effect of temperature on action potential encoding in the cockroach tactile spine. J. Comp. Physiol. A 156, 817-821.

French, A. S. and Järvilehto, M. (1978). The dynamic behaviour of photoreceptor cells in the fly in response to random (with noise) stimulation at a range if temperatures. J. Physiol., Lond. 274, 311-322.

Gabbiani, F., Krapp, H. and Laurent, G. (1999). Computation of object approach by a wide-field, motion-sensitive neuron. $J$. Neurosci. 19, 1122-1141.

Hausen, K. (1981). Monocular and binocular computation of motion in the lobula plate of the fly. Verh. Dt. Zool. Ges. 74, 49-70. 


\section{A.-K. WARZECha, W. Horstmann AND M. EgelhaAF}

Hausen, K. (1982). Motion sensitive interneurons in the optomotor system of the fly. I. The horizontal cells: Structure and signals. Biol. Cybernetics 45, 143-156.

Hausen, K. and Egelhaaf, M. (1989). Neural mechanisms of visual course control in insects. In Facets of Vision (ed. D. Stavenga and R. Hardie), pp. 391-424. Berlin, Heidelberg, New York: SpringerVerlag.

Heinrich, B. (1993). The Hot-Blooded Insects. Berlin, Heidelberg, New York: Springer-Verlag.

Hille, B. (1992). Ionic Channels of Excitable Membranes. Sunderland: Sinauer Associates Inc.

Horstmann, W., Warzecha, A.-K. and Egelhaaf, M. (1999). Synaptic transmission and postsynaptic integration in motion sensitive neurons of the fly (Calliphora). In Göttingen Neurobiology Report 1999 (ed. N. Elsner and U. Eysel), p. 444. Stuttgart, New York: Thieme.

Janssen, R. (1992). Thermal influences on nervous system function. Neurosci. Biobehav. Rev. 16, 399-413.

Katz, B. and Miledi, R. (1965). The measurement of synaptic delay and the time course of acetylcholine release at the neuromuscular junction. Proc. R. Soc. Lond. B 167, 8-22.

Kimmerle, B. (1999). Object detection by the fly Lucilia: Behavioral experiments in the flight simulator and performance of visual interneurons. Doctoral dissertation, University of Bielefeld, Germany.

Land, M. F. and Collett, T. S. (1974). Chasing behaviour of houseflies (Fannia canicularis). A description and analysis. $J$. Comp. Physiol. A 89, 331-357.

Maddess, T. and Laughlin, S. B. (1985). Adaptation of the motionsensitive neuron $\mathrm{H} 1$ is generated locally and governed by contrast frequency. Proc. R. Soc. Lond. B 225, 251-275.

Montogomery, J. C. and Macdonald, J. A. (1990). Effects of temperature on nervous system: Implications for behavioral performance. Am. J. Physiol. 28, R191-R196.

Roberts, S. P. and Harrison, J. F. (1999). Mechanisms of thermal stability during flight in the honeybee Apis mellifera. J. Exp. Biol. 202, 1523-1533.

Roberts, S. P., Harrison, J. F. and Hadley, N. F. (1998). Mechanisms of thermal balance in flying Centris pallida (Hymenoptera: Anthophoridae). J. Exp. Biol. 201, 2321-2331.
Robertson, R. M. (1993). Effects of temperature on synaptic potentials in the locust flight system. J. Neurophysiol. 79, 2197-2204.

Roebroek, J. G. H., Tjonger, M. V. and Stavenga, D. G. (1990). Temperature dependence of receptor potential and noise in fly (Calliphora erythrocephala) photoreceptor cells. J. Insect Physiol. 36, 499-505.

Rohlf, F. J. and Sokal, R. R. (1981). Statistical Tables. New York: Freeman.

Rowell, C. H. F., O'Shea, M. and Williams, J. L. D. (1977). The neuronal basis of a sensory analyzer, the acridid movement detector system. IV. The preference for small field stimuli. J. Exp. Biol. 68, 157-185.

Schmaranzer, S. and Kovac, H. (1996). Temperaturen von frei fliegenden Honigbienen. Verh. Dt. Zool. Ges. 89, 293.

Simmons, P. (1990). The effects of temperature on locust ocellar Lneurones and their interconnections. J. Comp. Physiol. A 166, $575-583$.

Sokal, R. R. and Rohlf, F. J. (1981). Biometry. New York: Freeman. Stavenga, D. G., Schwering, P. B. W. and Tinbergen, J. (1993). A three-compartment model describing temperature changes in tethered flying blowflies. J. Exp. Biol. 185, 326-333.

Tatler, B., O'Carroll, D. C. and Laughlin, S. B. (1999). Temperature, transduction and the temporal resolving power of fly photoreceptors. J. Comp. Physiol. A (in press).

Wagner, H. (1986). Flight performance and visual control of the flight of the free-flying housefly (Musca domestica). II. Pursuit of targets. Phil. Trans. R. Soc. Lond. B 312, 553-579.

Warzecha, A.-K. and Egelhaaf, M. (1996). Intrinsic properties of biological movement detectors prevent the optomotor control system from getting unstable. Phil. Trans. R. Soc. Lond. B 351, 1579-1591.

Warzecha, A.-K., Egelhaaf, M. and Borst, A. (1993). Neural circuit tuning fly visual interneurons to motion of small objects. I. Dissection of the circuit by pharmacological and photoinactivation techniques. J. Neurophysiol. 69, 329-339.

Weckström, M., Järvilehto, M., Kouvalainen, E. and Järvilehto, P. (1985). Fly photoreceptors and temperature: relative UV-sensitivity is increased by cooling. Eur. Biophys. 12, 173-179. 